\title{
EVALUATION OF THE POSSIBILITY OF THE SEWAGE SLUDGE GASIFICATION GAS USE AS A FUEL
}

\author{
OKREŚLENIE MOŻLIWOŚCI UŻYCIA GAZU \\ ZE ZGAZOWANIA OSADÓW ŚCIEKOWYCH JAKO PALIWA
}

\begin{abstract}
Biomass is one of the major sources of energy that is estimated to contribute between $10 \%$ and $14 \%$ of the world's energy supply. Over the past several years, many societies have established policy targets to increase their production of renewable energy from biomass. The thermo-chemical utilization of biomass includes 4 technologies: the most popular combustion and co-firing, and unconventional: pyrolysis and gasification. Gasification is considered to be the perspective technology because has many advantages in comparison to traditional process of combustion: (1) limited emission of the $\mathrm{SO}_{2}, \mathrm{NO}_{\mathrm{x}}$, oxides of the heavy metals and no risk of the dioxins and furans emission due to reducing atmosphere in the gasification reactor, (2) volume of the gasification gas is smaller in comparison to flue gases from combustion due to the reducing atmosphere, (3) gasification process produce gas which is potential gaseous fuel in power engineering (engines, gas turbines and boilers) and chemistry. Unfortunately, composition of the gasification gas is always described as a variable. Moreover, it depends on the conditions of the process and quality of the base fuel. For this reason, the use of gasification gas can't be very easy. For this reason, the knowledge of the basic properties of the gas is very important. Laminar burning velocity is assumed as an important quantity for in the process of the design equipment for the gas utilization. The numerical and experimental results of the laminar burning velocity of sewage sludge gasification gases were presented. Experimental Bunsen burner method was used. Cosilab $3^{\odot}$ software for numerical analysis was used. GRI-Mech 3.0 mechanism of gas oxidation was implemented. As a result of the work, the set of the parameters where the sewage sludge gasification gas combustion process is stable with effective heat release, were presented.
\end{abstract}

Keywords: laminar burning velocity, gasification gas, low calorific gas, Bunsen method, experimental study, numerical analysis

\section{Introduction}

The biomass gasification attracts increasing research activity in the area of energy. Biomass gasification gas with content of $\mathrm{H}_{2}, \mathrm{CO}, \mathrm{CH}_{4}$ and $\mathrm{N}_{2}, \mathrm{CO}_{2}, \mathrm{H}_{2} \mathrm{O}$ (inert component) is considered to be important for further conversion of the energy and utilization [1]. Nevertheless, there is huge variety of the biomass materials with various parameters.

\footnotetext{
${ }^{1}$ Institute of Thermal Technology, Silesian University of Technology, ul. S. Konarskiego 22, 44-100 Gliwice, Poland, phone +48 3223729 83, fax +48 3223728 72, email: sebastian.werle@ polsl.pl

${ }^{2}$ Institute of Water and Wastewater Engineering, Silesian University of Technology, ul. S. Konarskiego 18, 44-100 Gliwice, Poland, phone +48 32237 16 98, fax +48 3223710 47, email: mariusz.dudziak@ polsl.pl

*Corresponding author: sebastian.werle@polsl.pl
} 
Additionally gasification is characterized by changing operation parameters very often. As a result, gasification gas can be also characterized by various composition. Typically its composition varies from 4.0 to $50.4 \%$ hydrogen, $8.1-60.5 \%$ carbon monoxide, $1.3-29.6 \%$ carbon dioxide, $0-20.4 \%$ water vapor and $0-9.3 \%$ methane [2]. This attribute makes renders that process of the design the low emission combustion installation for gasification gas utilization is big challenge. Therefore, the understanding of the basic combustion properties of such gases with high level of the composition diversity is the most important. Among flame properties, the laminar burning velocity is regarded as an significant quantity due to it gives a basis information to turbulent combustion, and it also include the basic information on the reactivity. Moreover, the laminar burning velocity controls other important combustion characteristics, such as the flame's spatial distribution. Additionally, the laminar burning velocity is one of the key indicator that helps validate models of the chemical kinetic [3].

Different procedures have been described as a measurement method of burning velocity of gasification gas, such as flat flame, Bunsen flame, stagnation flame, spherically propagating flame, counter-flow flame and heat flux method [4-10].

Bunsen method is the most popular. This procedure is simple and flexible. Due to this fact, the laminar burning velocity of sewage sludge gasification gas was measured using this method. Wide range of air ratio under the atmospheric pressure and ambient temperature was used. Experimental results were compared with numerical data. Cosilab $3^{\odot}$ software for numerical analysis was used. GRI-Mech 3.0 mechanism of gas oxidation was implemented. As a result of the work, the set of the parameters where the sewage sludge gasification gas combustion process is stable with effective heat release, were presented.

\section{Experimental approaches - materials and methods}

Two types of the produced gas from the gasification of Polish granulated sewage sludge were analyzed. Sludge was taken from mechanical-biological and mechanical-biological-chemical wastewater treatment plants. Both samples were anaerobically digested and dehydrated. After anaerobic digestion, sewage sludge is dried. Table 1 presents main parameters of sewage sludge used.

Table 1

Main properties of the granulated sludge

\begin{tabular}{|c|c|c|}
\hline Main sludge properties & $\begin{array}{c}\text { Sewage sludge from } \\
\text { mechanical-biological wastewater }\end{array}$ & $\begin{array}{c}\text { Sewage sludge from } \\
\text { mechanical-biological-chemical } \\
\text { wastewater }\end{array}$ \\
\hline Moisture content [\% mass] & 5.30 & 5.30 \\
Volatile matter content [\% mass] & 51.00 & 49.00 \\
Ash content [\% mass] & 36.50 & 44.20 \\
Carbon [\% mass] & 31.79 & 27.72 \\
Hydrogen [\% mass] & 4.36 & 3.81 \\
Nitrogen [\% mass] & 4.88 & 3.59 \\
Oxygen [\% mass] & 57.07 & 63.04 \\
Sulphur [\% mass] & 1.67 & 1.81 \\
Fluoride [\% mass] & 0.013 & 0.003 \\
Chloride [\% mass] & 0.22 & 0.03 \\
The Lower Heating Value (LHV) & 12.96 & 10.75 \\
[MJ/kg] (on dry basis) & & \\
\hline
\end{tabular}


The gasification process of the sewage was carried out using a fixed bed installation [11]. Table 2 presents the composition of the analysed gasification gas.

Table 2

Composition of the analysed syngas

\begin{tabular}{|c|c|c|c|c|c|c|c|}
\hline \multirow{2}{*}{ Symbol } & \multirow{2}{*}{ Feedstock } & \multicolumn{6}{|c|}{ Syngas composition [\% vol.] } \\
\hline & & $\mathrm{CO}$ & $\mathrm{CO}_{2}$ & $\mathbf{H}_{2}$ & $\mathrm{CH}_{4}$ & $\mathbf{N}_{2}$ & $\mathrm{LHV}\left[\mathrm{MJ} / \mathrm{m}_{\mathrm{n}}^{3}\right]$ \\
\hline Syngas 1 & $\begin{array}{c}\text { Sewage sludge from } \\
\text { mechanical-biological } \\
\text { wastewater }\end{array}$ & 28.5 & 15.0 & 5.0 & 1.0 & 50.5 & 4.49 \\
\hline Syngas2 & $\begin{array}{l}\text { Sewage sludge from } \\
\text { mechanical-biological- } \\
\text { chemical wastewater }\end{array}$ & 25.0 & 18.0 & 3.5 & 0.8 & 52.7 & 3.81 \\
\hline
\end{tabular}

The main feature of the Bunsen burner method is that computation of the laminar burning velocity is based on the measurement of the main dimensions of the kinetic (inner) combustion cone and calculating the angle $\alpha$. The $\alpha$ parameter can be determined, as the angle between the slant height of inner cone and the base of this cone.

It was assumed in this method that the shape of the kinetic cone is an ideal and the velocity of the mixture is constant throughout the cross-section of the burner. The experiment was carried out for two different gas streams - 500 and $600 \mathrm{dm}^{3} / \mathrm{h}$ for both syngas compositions. The burner diameter was equal to $1.24 \mathrm{~cm}$. The experimental stand is showed in Figure 1.

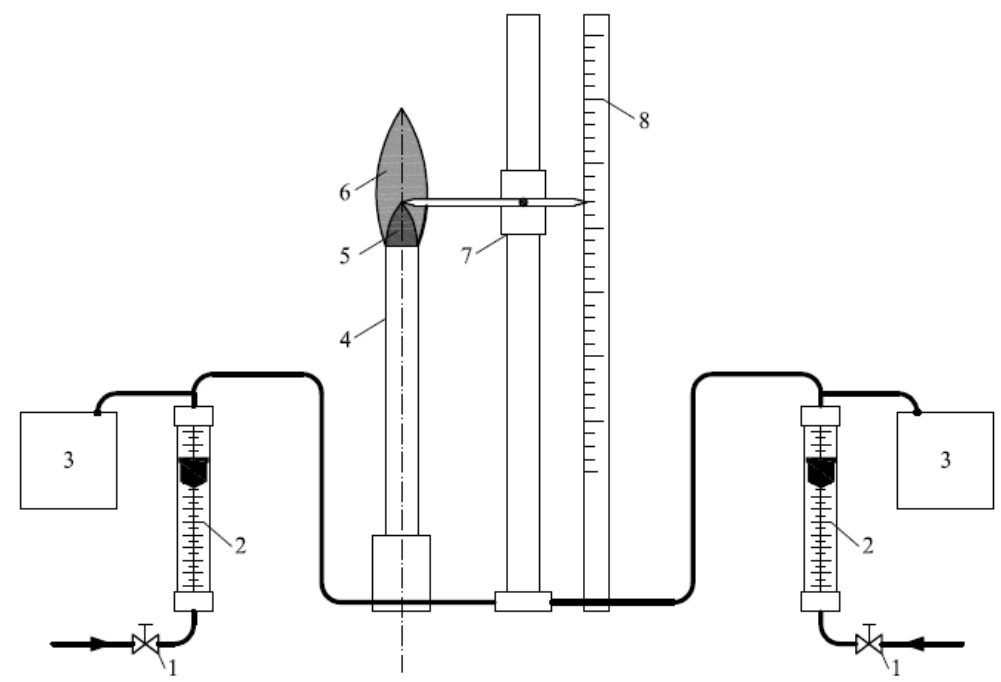

Fig. 1. Laboratory installation - the Bunsen burner method (1 - valves, 2 - rotameters, 3 - manometers, 4 - burner, 5 - inner combustion (kinetic) cone, 6 - outer (diffusive) combustion cone, 7 - stand with a movable pointer, 8 - ruler) 


\section{The calculation algorithm}

Effective flame speed was calculated using equation:

$$
S_{e}=\frac{\dot{V}_{g r}+\dot{V}_{a r}}{\pi \cdot \frac{D^{2}}{4}}
$$

where: $S_{e}$ - effective flame velocity $[\mathrm{m} / \mathrm{s}] ; \dot{V}_{g r}$ - real gas flow $\left[\mathrm{m}^{3} / \mathrm{s}\right] ; \dot{V}_{a r}$ - real air flow $\left[\mathrm{m}^{3} / \mathrm{s}\right] ; D$ - diameter of burner $[\mathrm{m}]$.

The air ratio $(\lambda)$ was calculated according equation (2). Following values was used: the combustion air and fuel ratio $\frac{m_{\text {air }}}{m_{\text {fuel }}}$, the minimum amount of air $\frac{1}{n_{\text {air } \min }}$ required for complete combustion and the molecular weight of air $\frac{1}{M_{\text {air }}}$ :

$$
\lambda=\frac{m_{\text {air }}}{m_{\text {fuel }} \cdot n_{\text {air } \min } \cdot M_{\text {air }}}
$$

The angle $\alpha$ was determined. The angle $\alpha$ is the angle between the laminar burning velocity vector and the effective flame velocity vector. Using the similarity of the triangles it can be realized that it has identical value as the angle between the burner radius $R$ and the kinetic slant height $H$ :

$$
\alpha=\operatorname{arctg}\left(\frac{H}{R}\right)
$$

Values $H$ and $R$ were measured during the experiment.

Laminar burning velocity $S_{L}$ was calculated using equation:

$$
S_{L}=S_{e} \cdot \cos \alpha
$$

\section{Laminar burning velocity simulation}

Kinetic analyses were determined using the 1D freely propagating flame model (FP1DLPF). Cosilab $3^{\odot}$ software was used. The domain of computation was equal to the range between 2 and $10 \mathrm{~cm}$. It was done to guarantee that the edge of the flame is far enough to eliminate influence of the heat and mass transfer through the boundary. During the computation, the pressure was equal to $0.1 \mathrm{MPa}$ and temperature of the mixture of the gas $-298 \mathrm{~K}$.

Four equations are base of the FP1DFPLF model: 1) the continuity, 2) the conservation of mass, 3) the energy and 4) the state of an ideal gas.

According to the thermal theory, a mathematical model of the laminar premixed flame enclose following assumptions:

- Heat, which is ensured due to an exothermic oxidation reaction, is transported thanks to conduction (no Dufour effect).

- Mass and heat transfer does not appear between particular stream layers. 
- The laminar flame thickness is relatively thin in comparison to the mean free path of a species.

For the kinetic simulation GRI-Mech 3.0 [12] mechanism was employed. The GRI-Mech 3.0, originally developed for $\mathrm{CH}_{4}$ combustion but recently it can be also use for other hydrocarbon fuels (eg propane and ethane). It consists of 325 reactions and 53 species. Moreover, this mechanism includes reactions that are involved in the combustion of other hydrocarbon fuels, such as ethane and propane. In recent years, this mechanism has also been employed for $\mathrm{CH}_{4} / \mathrm{H}_{2} /$ air [13] and $\mathrm{H}_{2} / \mathrm{CO} /$ air [14] flame simulations.

\section{Results and discussion}

Figure 2 shows laminar burning velocity values as a function of air ratio for two different gas streams -500 and $600 \mathrm{dm}^{3} / \mathrm{h}$ and for both analysed syngas.

The laminar burning velocity of analysed syngas reaches its maximum at fuel rich condition. It should be also concluded, that the laminar burning velocity value increases as the molar fraction of $\mathrm{H}_{2}$ in the fuel increase. In the case of the Syngas1 (molar fraction of hydrogen equal to $5 \%$ ) the laminar burning velocity is equal to $44.1 \mathrm{~cm} / \mathrm{s}$ (for volumetric gas streams equal to $500 \mathrm{dm}^{3} / \mathrm{h}$ ) and $41.0 \mathrm{~cm} / \mathrm{s}$ (for volumetric gas streams equal to $600 \mathrm{dm}^{3} / \mathrm{h}$ ) and in the case of Syngas2 (molar fraction of hydrogen equal to $3.5 \%$ ) $42.3 \mathrm{~cm} / \mathrm{s}$ (for volumetric gas streams equal to $500 \mathrm{dm}^{3} / \mathrm{h}$ ) and $32.0 \mathrm{~cm} / \mathrm{s}$ (for volumetric gas streams equal to $600 \mathrm{dm}^{3} / \mathrm{h}$ ).

This behavior is clarified by the facts that the fuel mixture reactivity increases with the increment of the $\mathrm{H}_{2}$ concentration. It can be explained by the fact that the diffusivity of the reactant mixture increase with decreasing of the molecular weight of gas.

This is cause by $\mathrm{CO}$ sensitivity to the presence of small amounts of $\mathrm{H}_{2}$. The $\mathrm{CO}$ oxidation shifts from slow reaction (R1) to fast reaction (R2) as the $\mathrm{H}_{2}$ amount increases, causing an increase in laminar burning velocity:

$$
\begin{gathered}
\mathrm{CO}+\mathrm{O} \rightarrow \mathrm{CO}_{2} \\
\mathrm{CO}+\mathrm{OH} \rightarrow \mathrm{CO}_{2}+\mathrm{H}
\end{gathered}
$$

Hydrogen is also characterized by completely different characteristic of combustion in comparison to other hydrocarbons fuels. As the concentration of $\mathrm{H}_{2}$ increases, the flame height declines. As a result, this positive effect induced by negative stretch on the local preferential diffusion at the flame tip is inhibited. However, the diffusion of the non-combusted fuel is promoted by the $\mathrm{H}_{2}$ increase and finally cause the decrease of the flame height. Above the value of the air ratio in which laminar burning velocity reaches its maximum, this parameter is decreasing. This behavior is caused by the habitancy of carbonyl compounds in the $\mathrm{H}_{2} / \mathrm{CO}$ blends. They are strongly influence on flame especially in the rich side of the laminar burning velocity curve.

Laminar burning velocity results achieved in experiment were compared with kinetic model results. The comparison of Syngas1 $\left(500 \mathrm{dm}^{3} / \mathrm{h}\right)$ results with kinetic predictions is presented on Figure 3. Analyzing these results, it can be said that experiment curve has a shape similar to the shape of a bell curve, which has a maximum at $\lambda \leq 1$. The obtained experimental results are only a fragment of the bell curve. 
a)

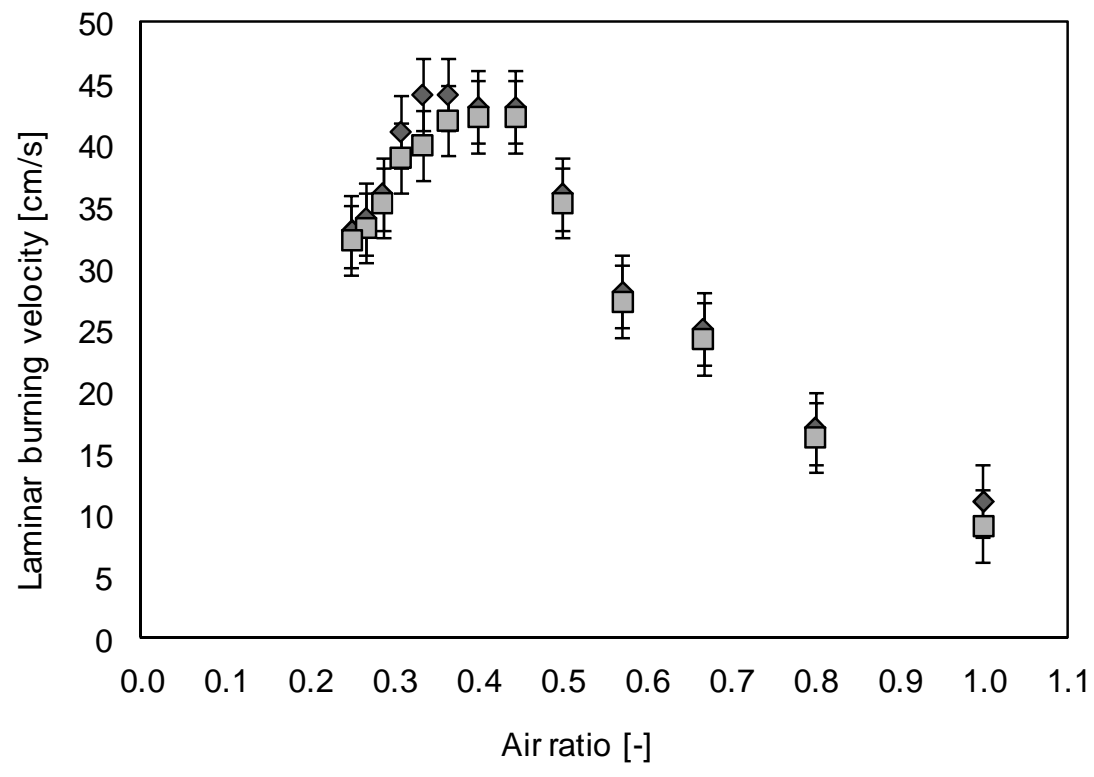

b)

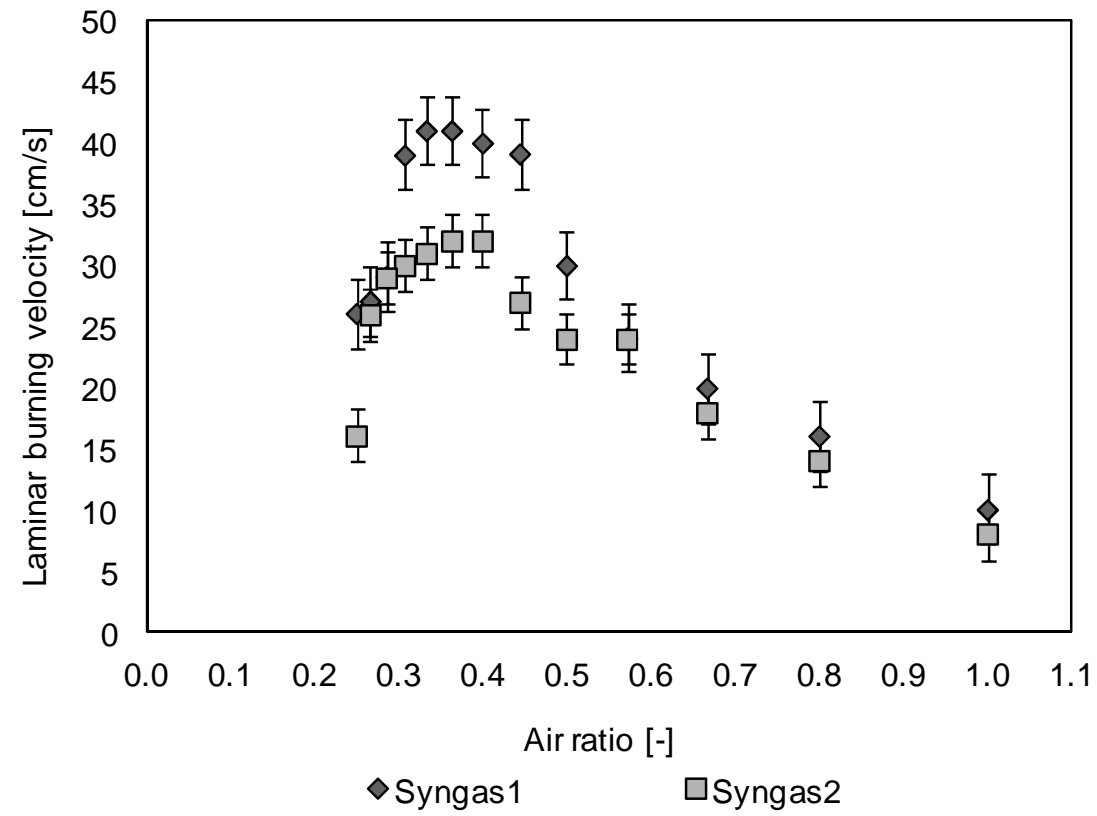

Fig. 2. Laminar burning velocity as a function of air ratio for two different gas streams: a) $500 \mathrm{dm}^{3} / \mathrm{h}$ and b) $600 \mathrm{dm}^{3} / \mathrm{h}$

Determination of the laminar burning velocity for higher air ratio values was not possible because the flame was blown off. Although the laminar burning velocity obtained 
by the Bunsen burner method wasn't adiabatic, the results showed to be very close to the kinetic prediction using GRI-Mech 3.0 mechanisms. Hence, the Bunsen flame can be used as a method to validate these kinetic results.

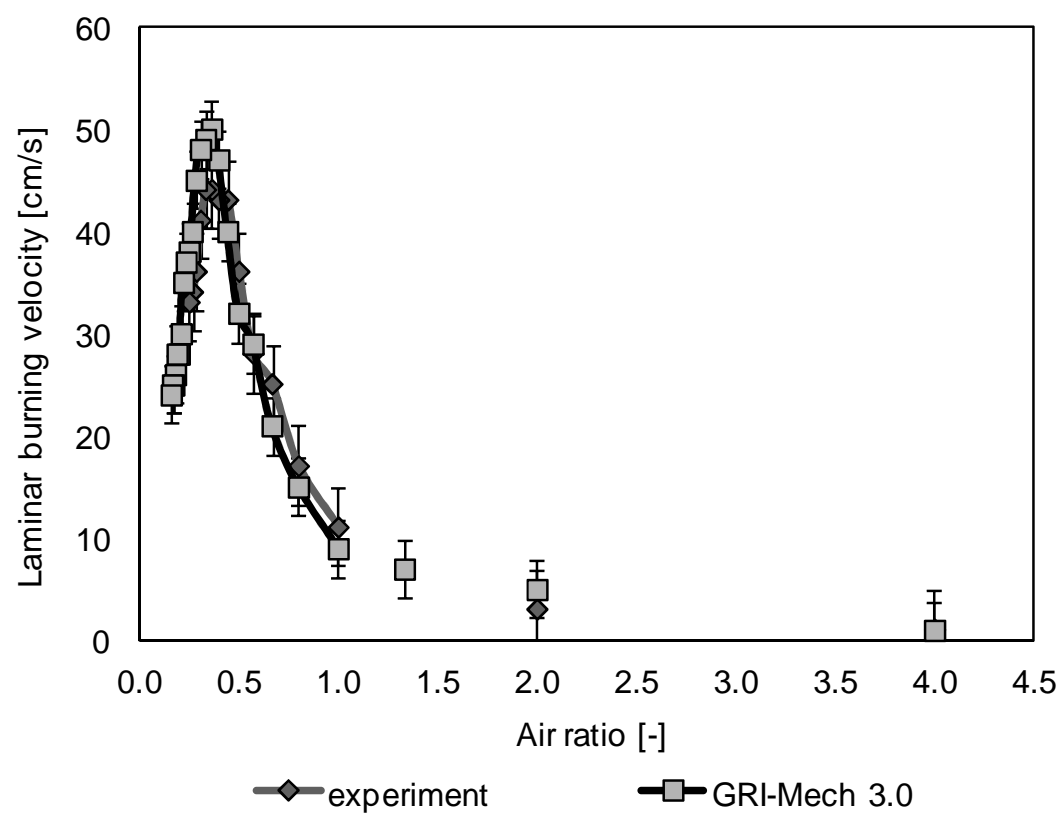

Fig. 3. Comparison of the experimental and numerical values of the laminar burning velocity for Syngas $1\left(500 \mathrm{dm}^{3} / \mathrm{h}\right)$

\section{Conclusions}

For the power and heat sector, gasified biomass can be used as a fuel in combustion devices such as gas engines, gas turbines, boilers or industrial burners. Particularly, use of the gasified biomass for final energy generation is foreseen as a promising application, possessing great potential for research and development. The combustion of gasification gas differs from that of natural gas particularly due to its different composition of heating value. Therefore, it is important crucial to understand the fundamental combustion parameters of syngas with different compositions.

Results show that the laminar burning velocity value increases with the increasing of the molar fraction of $\mathrm{H}_{2}$. This behavior is caused by the habitancy of carbonyl compounds in the $\mathrm{H}_{2} / \mathrm{CO}$ blends. The high diffusivity of $\mathrm{H}_{2}$ atoms and molecule influences the combustion characteristics of syngas.

Analyzing experimental results with kinetic prediction using GRI-Mech 3.0 mechanisms it can be realized that this simple, cheap and flexible method can be used to validate the simulation results. 


\section{Acknowledgments}

The paper has been prepared within the frame of the National Science Centre project based on decision no DEC-2011/03/D/ST8/04035.

\section{References}

[1] Wang ZH, Weng WB, He Y, Li ZS, Cen KF. Fuel. 2015;141:285-292. DOI: 10.1016/j.fuel.2014.10.040.

[2] Magdziarz A, Wilk M. J Therm Anal Calorim. 2013;114:519-529. DOI: 10.1007/s10973-012-2933-y.

[3] Magdziarz A, Wilk M, Kosturkiewicz B. Chem Process Eng. 2011;32:299-309. DOI: 10.2478/v10176-011-0024-4.

[4] Ouimette P, Seers P. Fuel. 2009;88:528-533. DOI: 10.1016/j.fuel.2008.10.008.

[5] Natarajan J, Kochar Y, Lieuwen T, Seitzman J. Proc Combust Inst. 2009;32:1261-1268. DOI: 10.1016/j.proci.2008.06.110.

[6] Burke MP, Chen Z, Ju Y, Dryer FL. Combust Flame. 2009;156(4):771-779. DOI: 10.1016/j.combustflame.2009.01.013.

[7] Bouvet N, Chauveau C, Gökalp I, Halter FP. Combust Inst. 2011;33:913-920. DOI: 10.1016/j.proci.2010.05.088.

[8] Bouvet N, Chauveau C, Gökalp I, Lee SY, Santoro RJ. Int J Hydrogen Energy. 2011;36:992-1005. DOI: 10.1016/j.ijhydene.2010.08.147.

[9] Hu E, Fu J, Pan L, Jiang X, Huang Z, Zhang Y. Int J Hydrogen Energy. 2012;37:18509-18519. DOI: 10.1016/j.ijhydene.2012.09.053.

[10] Fu J, Tang C, Jin W, Thi LD, Huang Z, Zhang Y. Int J Hydrogen Energy. 2013;38:1636-1643. DOI: 10.1016/j.ijhydene.2012.11.023.

[11] Werle S, Dudziak M. Energies. 2012;19:137-144. DOI: 10.3390/en7010462.

[12] Smith GP, Golden DM, Frenklach M, Moriarty NW, Eiteneer B, Goldenberg M. GRI-Mech 3.0 http://ww.me.berkeley.edu/gri_mech/.

[13] Halter F, Chauveau C, Djeballi-Chaumeix N, Gokalp I. P Combust Inst. 2005;30:201-208. DOI: 10.1016/j.proci.2004.08.195.

[14] Natarajan J, Lieuwen T, Seitzman J. Combust Flame. 2007;151:104-119. DOI: 10.1016/j.combustflame.2007.05.003. 